\title{
Construct Validity of a Virtual Reality Simulator for Surgical Training in Knee Arthroscopy
}

\author{
Miguel J. Palet ${ }^{1}$, Marcela Antúnez-Riveros ${ }^{2}$, Maximiliano Barahona ${ }^{1}$ \\ 1. Department of Orthopedic Surgery, Faculty of Medicine, University of Chile, Santiago, CHL 2. Department of Health \\ Sciences Education, Faculty of Medicine, University of Chile, Santiago, CHL
}

Corresponding author: Miguel J. Palet, miguelpalet@uchile.cl

\section{Abstract \\ Objective}

Surgical techniques are learned gradually throughout an orthopedic residency. Training on real patients carries drawbacks such as limited access and elevated risk. Alternatively, surgical simulation allows residents to practice in a safe environment with greater access to standardized surgical tasks. Virtual reality simulators display images inside an artificial joint, often providing real-time haptic feedback to allow for realistic interaction. The objective of this study was to evaluate the construct validity of a virtual reality simulator for knee arthroscopy by analyzing the capacity of system parameters to distinguish between expert and novice surgeons.

\section{Design}

This comparative cross-sectional study contrasts the automated performance reports for novice and expert orthopedic surgeons after executing surgical tasks on the ARTHRO Mentor virtual reality simulator.

\section{Setting}

Surgical simulation center at the University of Chile Clinical Hospital, Santiago, Chile.

\section{Participants}

The novice group consisted of 20 second-year orthopedic and traumatology residents at the University of Chile School of Medicine. The expert group consisted of 10 experienced arthroscopic surgeons. All participants carried out standardized tasks in the knee arthroscopy virtual reality simulator. The median performance scores of the two groups were compared, and multivariate logistic regression was performed to assess the capacity of the system to discriminate between the two groups.

\section{Results}

Review began 05/14/2021 Review ended 05/23/2021 Published 05/25/2021

\section{() Copyright 2021}

Palet et al. This is an open access article distributed under the terms of the Creative Commons Attribution License CC-BY 4.0., which permits unrestricted use, distribution, and reproduction in any medium, provided the original author and source are credited.
Median performance on the vast majority of surgical tasks was superior for the expert group. The expert group had performance values equal to or higher than the novice group on 43 of the 44 variables recorded for the basic tasks and 74 of the 75 advanced task variables. The multivariate logistic regression analysis discriminated expert from novice users with $100 \%$ accuracy.

\section{Conclusion}

The virtual reality simulator for knee arthroscopy showed good construct validity, with performance metrics accurately discriminating between expert and novice users.

Categories: Medical Education, Medical Simulation, Orthopedics

Keywords: arthroscopy, knee, simulation training, surgical simulation, virtual reality

\section{Introduction}

Arthroscopy has become the gold standard for treating joint pathology. Knee arthroscopy is the most commonly performed traumatological procedure in the United States [1] and, likewise, at the University of Chile Clinical Hospital where this study took place. Surgery has classically been taught in the operating room by an expert, using real patients [2-4], with all of the difficulties that this approach involves. Drawbacks of training with real patients include high cost [4] and, more significantly, increased risk for patients [5]. Given that medical errors are the third-leading cause of death in the United States [6], this risk is no longer tolerable. Current surgical procedures require a learning curve to minimize errors that can be more frequent and severe in less experienced hands [7]. Practical training opportunities may be limited for orthopedic and traumatology students due to patient's safety, along with regulations reducing the weekly schedule for residents to 80 hours [8]. To improve the quality of surgical training, therefore, programs have introduced simulation training, including the use of bench models, live animals, cadavers, high fidelity 
simulators, and virtual reality surgical simulators [3,9]. The basic concept of these approaches is that the first stages of surgical training can take place outside the operating room, with residents proceeding to train on real patients after having achieved a skill level equivalent to the automation stage of learning in the Fitts and Posner model [10], performing tasks with speed and precision [11] or the competent stage of the Dreyfus model [12,13]. Virtual reality simulations, based on the technology pioneered in aviation simulation [14], make use of computerized phantom extremities displaying the inside of a joint on a screen. The student performs procedures inside the phantom joint using system-linked instruments that provide instantaneous haptic feedback. This training qualifies as deliberative practice [15], as it presents short tasks to motivated subjects, offering immediate feedback and the opportunity for multiple repetitions. Preliminary evidence suggests that this teaching method is useful; for instance, virtual reality simulation has been shown to reduce operating times in laparoscopic surgery [16]. In addition to its utility as a teaching tool, simulation provides a way to evaluate performance. Considering the Miller pyramid for assessing clinical skills, surgical simulation corresponds to the third level of competence, or demonstration of learning [17]. In the Miller model, the third and fourth levels ("shows how" and "does") represent the behavioral levels of competence. Virtual reality simulators provide an automated numerical report after each task, supplying an objective measure of the performance [18].

The validity of simulated training can be assessed along five dimensions [19-21]. Face validity is the subjective degree to which the model resembles the real surgical situation. Content validity reflects the extent to which the model covers the relevant aspects of the real situation. Both of these types of validity can be measured using surveys. Construct validity is the capacity of the system to effectively simulate the relevant skill and to discriminate between expert and novice performance $[20,22,23]$. Concurrent validity measures agreement between the simulator and another type of previously validated assessment. Finally, predictive validity is the capacity of the simulator to predict the clinical performance of subjects exposed to the training model, measuring the transfer of skills to the real surgical environment $[2,21,24,25]$.

In Chile, there has been no reported evidence to date regarding the use of virtual reality simulators in traumatology programs, although surgical simulation has been studied [26] and validated [27] in the context of laparoscopic surgery.

The objective of this study was to evaluate the construct validity of a knee arthroscopy virtual reality simulator used in an orthopedic surgeon residency program.

\section{Materials And Methods}

\section{Study design}

A comparative cross-sectional study was conducted to evaluate the automated performance reports produced by the ARTHRO Mentor ${ }^{\mathrm{TM}}$ knee arthroscopy simulator (SimbionixTM, Cleveland, OH, USA), comparing the performance of novice and expert orthopedic surgeons.

\section{Participants}

All 20 second-year residents in the traumatology and orthopedic program at the University of Chile School of Medicine were enrolled in the study and assigned to the "novice" group. The expert group was made up of 10 attending traumatologists from the same department with experience in arthroscopy. The inclusion criteria for the expert group were: formal academic education in arthroscopy, surgical arthroscopy, or sports traumatology; at least three years of experience in arthroscopic surgery; and at least 500 arthroscopic procedures completed [19]. Sample size calculations were not performed and the participant number was defined according to their availability; in the case of the students, all second-year residents were included, and in the case of the experts, all participants who met inclusion criteria and agreed to participate were enrolled.

\section{Definition of tasks}

The surgical tasks were defined as the standardized modules for the Simbionix ${ }^{\mathrm{TM}}$ ARTHRO Mentor ${ }^{\mathrm{TM}}$ knee arthroscopy simulator (Figure 1). 


\section{Cureus}

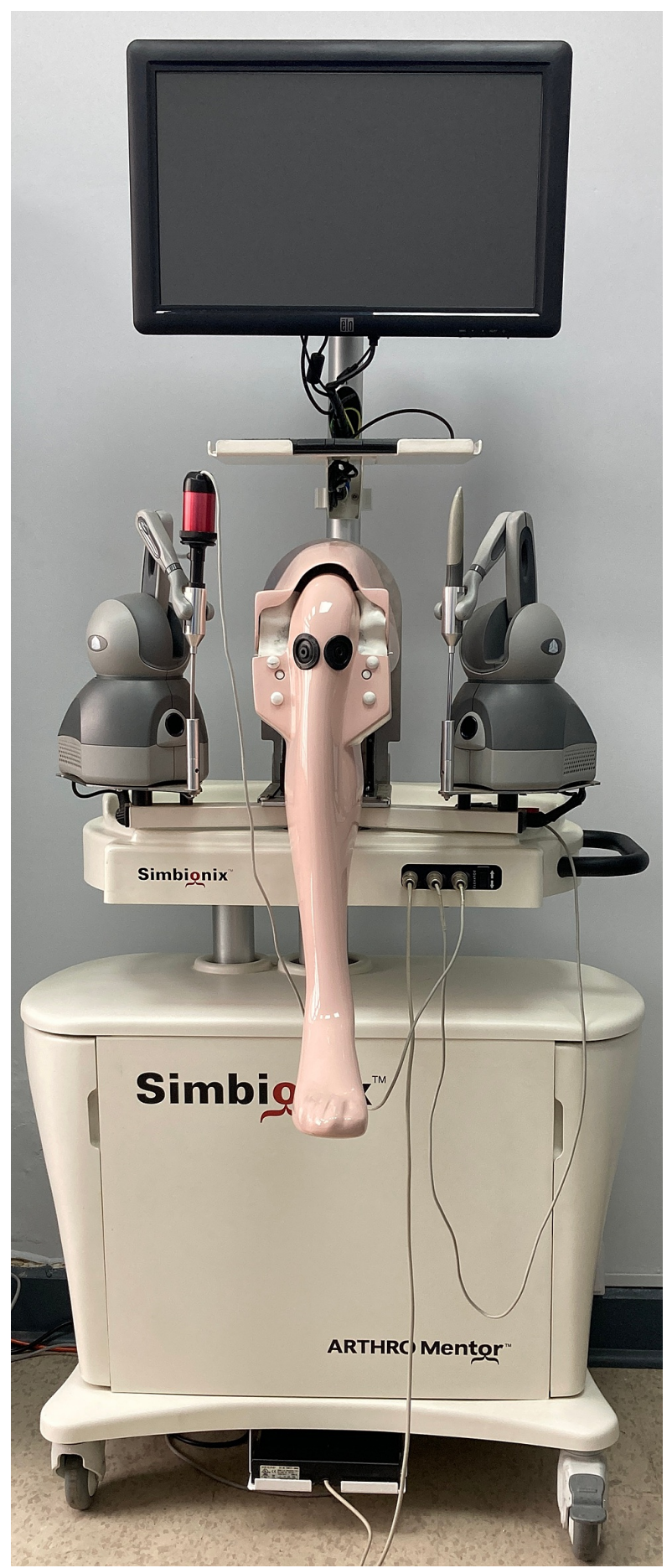

\section{FIGURE 1: ARTHRO Mentor ${ }^{\text {TM }}$ knee arthroscopy simulator}

The basic tasks were defined as the 11 exercises in the FAST (Fundamentals of Arthroscopic Surgery Training) course included in the simulator software. These tasks were: steadiness of the camera and arthroscope, image orientation, image centering, telescoping, deliberate linear scope motion, periscoping, tracking a moving target with the scope, basic probe triangulation, touch and probe of a stationary target, simultaneous image tracking and probing of a moving target, and measurement of articular dimensions with the tip of a probe.

The seven advanced techniques were: arthroscopic visual examination, diagnostic arthroscopy with advance probe examination, diagnostic arthroscopy of a random intra-articular pathology, meniscectomy of a radial lateral tear, loose body removal, femoral condyle repair with microfractures, and tunnel placement for anterior cruciate ligament (ACL) reconstruction. 
The simulator records a series of performance parameters for each task. Most of the exercises include the following parameters: completion time, the accuracy of camera and instrument use, percentage time in partial and perfect alignment, arthroscope path distance, and camera path distance. For the advanced procedures, additional safety parameters are included: camera collisions with the tissue and capsule, blind use of instruments, and iatrogenic chondral damage.

All procedures were carried out at the surgical simulation centers in the University of Chile Clinical Hospital, under the direction of the principal investigator.

All novices and experts $(n=30)$ performed 18 tasks. The students received instantaneous feedback from an expert after finishing each task and were given the opportunity to repeat the tasks using the suggestions and corrections provided. However, only the scores for the first attempt of both groups were used for the study analysis. The performance data generated automatically by the simulator software for the first attempt at each task by each subject were recorded; no performance thresholds were applied. The simulator recorded a total of 238 variables for the 18 tasks for each subject. Some variables were fixed rather than varying according to performance. As these variables were identical for all participants, they were not analyzed. Finally, the remaining 119 metrics from the 18 tasks were saved in an Excel (Microsoft) spreadsheet for a total of 30 subjects, 20 novices, and 10 experts.

\section{Statistical analysis}

Descriptive and inferential statistics were performed using Stata 15 software (StataCorp CP, College Station, TX, USA). Considering the data distribution, nonparametric analyses were performed, Wilcoxon nonparametric medians difference test was used for unpaired samples to compare the median scores between groups [28]. A multivariate logistic regression analysis was also performed using a priori probability information [29]. Statistical significance was defined as $\mathrm{p}<0.05$ for differences between groups.

\section{Results}

The group of 20 novices included all of the second-year residents in the program. None of the residents had previous experience with surgical simulators or surgical arthroscopy. The age range was 26 to 39 years, and all were male. All 10 experts were surgeons experienced in knee arthroscopy; three also had experience with cadaveric arthroscopy and three with shoulder arthroscopy. The age range was 38 to 59 years, and all were male.

The experts had superior performance results for the vast majority of tasks. A total of 44 variables were recorded for the 11 tasks in the basic FAST course. The median expert score was equal to or higher than the median novice score on 43 (98\%) of these variables. The novice score was higher on only one variable, the number of times that probe was out of contact, in task 10, but this difference was not significant. The detailed results for the FAST tasks were as follows:

Basic task 1, steadiness of the camera and arthroscope: Both novices and experts demonstrated perfect accuracy and alignment.

Basic task 2, image orientation: Accuracy was worse for novices than experts. The percentage of time in perfect alignment was worse for novices than experts. The efficiency of rotational movement was worse for novices than experts.

Basic task 3, image centering: Accuracy was significantly higher among experts than novices ( $\mathrm{p}=0.0414)$. The experts were also faster than the novices $(\mathrm{p}=0.0399)$. The efficiency of movement metrics was also higher for the experts than the novices ( $\mathrm{p}=0.0248$ ) percentage of time in perfect alignment was also better in the expert group but this difference was not significant.

Basic task 4, telescoping: Time in perfect alignment was significantly higher for the expert group ( $\mathrm{p}=0.0075)$. The percentage of time in perfect alignment was worse for novices than experts, but this difference was not significant.

Basic task 5, deliberate linear scope motion: The performance was superior for the expert vs. novice group for all four variables, but only in three the difference was significant. Time in perfect alignment $(\mathrm{p}=0.0206)$, efficiency of linear movement $(\mathrm{p}=0.0094)$, and total time $(\mathrm{p}=0.0036)$.

Basic task 6, periscoping: The performance was significantly superior for the expert vs. novice group for all five variables: accuracy, time in perfect alignment, periscope efficiency, camera movement, and total time.

Basic task 7, tracking a moving target with the scope: Differences between groups were not statistically significant.

Basic task 8, basic probe triangulation: The expert group had significantly superior performance on three of 
four variables: probe accuracy $(\mathrm{p}=0.0082)$, time in perfect alignment $(\mathrm{p}=0.023)$, and total time $(\mathrm{p}=0.0002)$.

Basic task 9, touch and probe of a stationary target: The expert performance was superior to novice performance for all three variables, but the only statistically significant difference was for total time $(\mathrm{p}=0.0093)$.

Basic task 10, simultaneous image tracking and probing of a moving target: The expert performance was superior for two of three variables. The number of times that probe was out of contact was the only variable that novices had superior performance than experts. The differences were not statistically significant for the three variables.

Basic task 11, measurement of articular dimensions with the tip of a probe: The expert performance was superior to novice performance for all three variables, with statistically significant differences for two: efficiency of measurement $(\mathrm{p}=0.0012)$ and total time $(\mathrm{p}=0.0073)$.

Table 1 compares expert with novice performance on the FAST course tasks, showing 35 of the 44 variables recorded. The remaining 11 variables were percentages of time in partial alignment, which corresponded to a value of $100 \%$ minus the given value for time in perfect alignment.

\begin{tabular}{|c|c|c|c|c|}
\hline \multicolumn{2}{|l|}{ Task } & $\begin{array}{l}\text { Median novice } \\
\text { score }\end{array}$ & $\begin{array}{l}\text { Median expert } \\
\text { score }\end{array}$ & $\begin{array}{l}\text { Statistical significance (p- } \\
\text { value) }\end{array}$ \\
\hline \multirow{2}{*}{ FAST 1} & Percentage of accuracy & 100 & 100 & 0.2398 \\
\hline & Percentage of tıme in perfect alıgnment & 100 & 100 & 0.2211 \\
\hline \multirow{3}{*}{ FAST 2} & Percentage of accuracy & 50 & 66 & 0.0923 \\
\hline & Percentage of time in perfect alignment & 97.5 & 99 & 0.5156 \\
\hline & Eftıciency of rotatıonal movement & 50.1 & 65 & 0.078 \\
\hline \multirow{4}{*}{ FAST 3} & Percentage of accuracy & 63 & 73.5 & 0.0414 \\
\hline & Percentage of time in perfect alignment & 90.5 & 94 & 0.1514 \\
\hline & Efficiency of movements & 64 & 88 & 0.0248 \\
\hline & Total tıme & 45 & 31.5 & 0.0399 \\
\hline \multirow{2}{*}{ FASI 4} & Percentage of tıme out of alıgnment & 2.5 & 1.5 & 0.273 \\
\hline & Percentage of time in perfect alignment & 95 & 98 & 0.0075 \\
\hline \multirow{4}{*}{ FAST 5} & Percentage of accuracy & 70.5 & 85 & 0.097 \\
\hline & Percentage of time in perfect alignment & 75 & 83 & 0.0206 \\
\hline & Efficiency of linear movement & 43 & 73 & 0.0094 \\
\hline & Total time & 28.5 & 26.5 & 0.0036 \\
\hline \multirow{5}{*}{ FAST 6} & Percentage of accuracy & 28.5 & 45.5 & 0.0243 \\
\hline & Percentage of tıme in perfect alıgnment & 58.5 & 71 & 0.0262 \\
\hline & Periscope efficiency & 39 & 67 & 0.0008 \\
\hline & Camera movement & 108 & 18.5 & 0.00001 \\
\hline & Total time & 269.5 & 110 & 0.00001 \\
\hline \multirow{2}{*}{ FAST 7} & Percentage of time out of alignment & 0 & 0 & 0.1201 \\
\hline & Percentage of time in perfect alignment & 97,5 & 98 & 0.2257 \\
\hline \multirow{4}{*}{ FASI 8} & Percentage of probe accuracy & 50 & 66 & 0.0082 \\
\hline & Percentage of time in perfect alignment & 82.5 & 87 & 0.023 \\
\hline & Probe efficiency & 81.5 & 8 & 0.659 \\
\hline & Total time & 145 & 60 & 0.0002 \\
\hline
\end{tabular}




\section{Cureus}

\begin{tabular}{|c|c|c|c|c|}
\hline \multirow{3}{*}{ FAST 9} & Percentage of probe accuracy & 54 & 60 & 0.8766 \\
\hline & Probe efficiency & 100 & 100 & 0.5639 \\
\hline & Total time & 49.5 & 39.5 & 0.0093 \\
\hline \multirow{3}{*}{ FAST 10} & $\begin{array}{l}\text { Number of times that probe was out of } \\
\text { contact }\end{array}$ & 4,5 & 5.5 & 0.8418 \\
\hline & Percentage of time in perfect alignment & 93 & 94.5 & 0.4145 \\
\hline & Efficiency of probe movement & 35.5 & 40 & 0.8258 \\
\hline \multirow{3}{*}{ FAST 11} & Attempts before successful task completion & 2 & 1.5 & 0.3477 \\
\hline & Efficiency of measurement & 16 & 52.5 & 0.0012 \\
\hline & Total accumulated time & 191.5 & 69.5 & 0.0073 \\
\hline
\end{tabular}

\section{TABLE 1: Comparison of novice and expert performance in basic FAST task metrics}

Time is in seconds, distances in centimeter, attempts in the number of times. Other scores are calculated as a percentage.

The experts performed the six timed basic tasks significantly faster than the novice surgeons, all with statistical significance $(\mathrm{p}<0.05)$ (Figure 2$)$. The expert performance was significantly superior to novice performance for 22 of the 44 variables in the basic tasks (50\%).

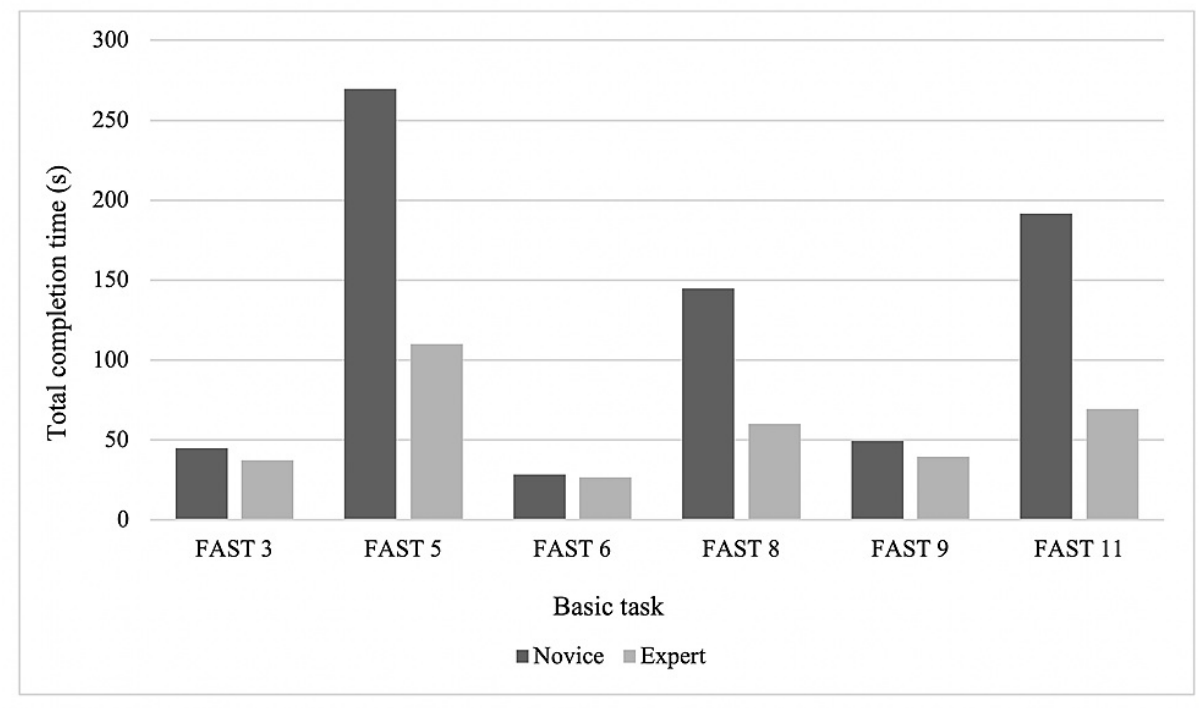

\section{FIGURE 2: Median completion time for basic tasks}

Comparison of the time required for novices vs. experts to complete each basic FAST task for which this variable was recorded. Results are expressed in seconds. All differences were statistically significant $(p<0.05)$.

A total of 75 variables were recorded for advanced tasks. The performance of the experts was superior to that of the novices for the vast majority of these tasks.

Advanced task 1, arthroscopic visual examination: The performance of the expert group was superior for all six variables, and five of these differences were statistically significant: total time, total camera distance, number of collisions with the capsule, number of camera-tissue collisions, and the average time to locate a target. The experts also showed superior performance for the percentage of camera steadiness, but this difference was not significant $(\mathrm{p}=0.3099)$.

Advanced task 2, diagnostic arthroscopy with advance probe examination: Notably, expert performance 
values were higher than novice values for all 11 variables, and 10 of these differences were statistically significant. The median completion time for the expert group was about half that of the novice time (170.5 vs. $346 \mathrm{~s})(\mathrm{p}<0.00001)$. Furthermore, total camera and probe distances were approximately half the novice distances ( 47 vs. 123 and 103.5 vs. $208 \mathrm{~cm}$, respectively) ( $\mathrm{p}=0.0003$ and $\mathrm{p}=0.0056$ ). Finally, the experts had fewer camera-tissue collisions $(\mathrm{p}=0.0001)$ or collisions with the capsule $(\mathrm{p}=0.023)$ and fewer instances of blind probing $(\mathrm{p}=0.0005)$.

Advanced task 3, diagnostic arthroscopy of a random intra-articular pathology: The expert performance was superior to novice performance for all eight variables, and five of the differences were statistically significant. Completion time was markedly faster for the expert vs. novice group ( $p<0.00001)$, and the experts did not commit any errors in identifying intra-articular pathologies nor did they omit any pathologies. The novices, in contrast, only had 65\% (13/20) accuracy in identifying pathologies and omitted $35 \%(7 / 20)$ of pathologies.

Advanced task 4, meniscectomy of a radial lateral tear: For this task, the participants were asked to perform a partial meniscectomy for a radial lesion of the lateral meniscus. A total of 22 variables were recorded. Performance values were significantly higher for the expert group on half of these variables. Notably, in terms of safety, the experts did not cause any cartilage damage, unlike the novices ( $0 \mathrm{vs} .58 \mathrm{~mm}^{2}$ of area damaged) ( $\mathrm{p}=0.0392)$ and had fewer camera-tissue collisions ( 7.5 vs. 16) ( $\mathrm{p}=0.001)$.

The system provided an automatic overall score for advanced tasks 5 to 7 , from 0 to 10 .

Advanced task 5, loose body removal: five of the nine metrics was statistically significant. The overall scores for the expert group were significantly higher than those of the novices (7.2 vs. 4.7) ( $\mathrm{p}=0.0004)$. Completion time was again markedly faster for the expert group (64 vs. $151.5 \mathrm{~s})(\mathrm{p}=0.0001)$, and the camera and instrument path lengths were notably shorter for the expert vs. novice group.

Advanced task 6, femoral condyle repair with microfractures: The median expert score was equal or higher than that of the novices for 10 of the 11 variables recorded. The novice values were higher for one variable, but this difference was not statistically significant. While overall scores were similar ( $7.5 \mathrm{vs}$. 7.2 for the experts vs. novices), the completion time was markedly faster for the experts (143 vs. $260.5 \mathrm{~s})$ ( $\mathrm{p}=0.0003$ ).

Advanced task 7, tunnel placement for ACL reconstruction with single-band technique: The expert performance was superior to that of novices for all eight variables recorded, and the differences were statistically significant for seven metrics. Notably, the completion time was faster for the expert vs. novice group (99.5 vs. $139.5 \mathrm{~s})$ ( $\mathrm{p}=0.0003)$, and the overall score was higher (8.6 vs. 6.1) $(\mathrm{p}<0.00001)$.

The data for the advanced tasks and the statistical significance are shown in Table 2.

\begin{tabular}{|c|c|c|c|c|}
\hline \multicolumn{2}{|l|}{ Task } & $\begin{array}{l}\text { Median } \\
\text { novice score }\end{array}$ & $\begin{array}{l}\text { Median } \\
\text { expert score }\end{array}$ & $\begin{array}{l}\text { Statistical } \\
\text { significance (p-value) }\end{array}$ \\
\hline \multirow{6}{*}{ 1. Arthroscopic visual examination } & Total time & 191 & 114 & 0.0007 \\
\hline & I otal camera distance & 113.5 & 71 & 0.0045 \\
\hline & $\begin{array}{l}\text { Number of collisions with the } \\
\text { capsule }\end{array}$ & 14 & 9.5 & 0.0103 \\
\hline & $\begin{array}{l}\text { Number of camera- tissue } \\
\text { collisions }\end{array}$ & 68.5 & 45 & $0.003 /$ \\
\hline & $\begin{array}{l}\text { Percentage of camera } \\
\text { steadiness }\end{array}$ & 61 & 69 & 0.3099 \\
\hline & Average tıme to locate a target & 19 & 11 & 0.0001 \\
\hline & Total time & 346 & 170.5 & 0.0001 \\
\hline & Total camera distance & 123 & 47 & 0.0003 \\
\hline & Total tool distance & 208 & 103.5 & 0.0056 \\
\hline & $\begin{array}{l}\text { Number of camera-tissue } \\
\text { collisions }\end{array}$ & 16 & 7 & 0.0001 \\
\hline & $\begin{array}{l}\text { collisions } \\
\text { col camera-tissue }\end{array}$ & 105 & 53 & $0.00 / 3$ \\
\hline
\end{tabular}




\section{Cureus}

2. Diagnostic arthroscopy with advance probe examination

3. Diagnostic arthroscopy of a random intra-articular pathology

\begin{tabular}{|c|c|c|c|}
\hline $\begin{array}{l}\text { Total time of blind tissue } \\
\text { probing }\end{array}$ & 20 & 4 & 0.0005 \\
\hline $\begin{array}{l}\text { Number of times irrelevant } \\
\text { organs were touched }\end{array}$ & 35 & 19.5 & 0.0015 \\
\hline $\begin{array}{l}\text { Total distance tools were moved } \\
\text { blindly }\end{array}$ & 92.5 & 33 & 0.0006 \\
\hline $\begin{array}{l}\text { Number of collisions with the } \\
\text { capsule }\end{array}$ & 8 & 4 & 23 \\
\hline Percentage of probe steadiness & 19.5 & 20.5 & 0.8087 \\
\hline Average time to probe a target & 38.5 & 18.5 & $<0.00001$ \\
\hline Total time & 262 & 73.5 & $<0.00001$ \\
\hline Total camera distance & 130 & 44.5 & $<0.00001$ \\
\hline $\begin{array}{l}\text { Number of camera- tissue } \\
\text { collisions }\end{array}$ & 17 & 5.5 & $<0.00001$ \\
\hline $\begin{array}{l}\text { Total time of camera- tissue } \\
\text { collisions }\end{array}$ & 78 & 17 & 0.0002 \\
\hline $\begin{array}{l}\text { Number of collisions with the } \\
\text { capsule }\end{array}$ & 0 & 0 & 0.1364 \\
\hline $\begin{array}{l}\text { Identification of correct } \\
\text { pathology }\end{array}$ & $13 / 20$ & $10 / 10$ & NA \\
\hline $\begin{array}{l}\text { Omission of intra-articular } \\
\text { pathology }\end{array}$ & $7 / 20$ & $0 / 10$ & NA \\
\hline $\begin{array}{l}\text { Percentage of the articular area } \\
\text { examined }\end{array}$ & 80 & 90 & 0.0062 \\
\hline Total time & 355.5 & 183.5 & 0.0004 \\
\hline Total camera distance & 50.5 & 17.5 & 0.0002 \\
\hline Total tool distance & 165.5 & 97.5 & 0.0366 \\
\hline $\begin{array}{l}\text { Number of camera- tissue } \\
\text { collisions }\end{array}$ & 16 & 7.5 & 1 \\
\hline $\begin{array}{l}\text { Total time of camera- tissue } \\
\text { collisions }\end{array}$ & 150.5 & 50 & 0.0155 \\
\hline $\begin{array}{l}\text { Total distance tools were moved } \\
\text { blindly }\end{array}$ & 71 & 37.5 & 0.0248 \\
\hline $\begin{array}{l}\text { Total time tools were moved } \\
\text { blindly }\end{array}$ & 53.5 & 30 & 0.0064 \\
\hline $\begin{array}{l}\text { Number of collisions with the } \\
\text { capsule }\end{array}$ & 2 & 2 & 0.5011 \\
\hline Diagnostic time & 63 & 52.5 & 0.1591 \\
\hline Percentage of palpated tear & 18.5 & 61 & 0.2984 \\
\hline Time punch was used & 118.5 & 64 & 0.0146 \\
\hline Punch movement & 67.5 & 39.5 & 202 \\
\hline Number of blind punching & 2 & 1 & 0.1178 \\
\hline $\begin{array}{l}\text { Number of times an irrelevant } \\
\text { organ was touched }\end{array}$ & 22 & 16 & 0.1587 \\
\hline $\begin{array}{l}\text { Distance of open punch } \\
\text { movement }\end{array}$ & 61.5 & 28.5 & 0.0677 \\
\hline Percentage of remaining & & & \\
\hline
\end{tabular}




\section{Cureus}

5. Loose body extraction

6. Femoral condyle repair with microfractures

7. Tunnel placement for ACL reconstruction

\begin{tabular}{|c|c|c|c|}
\hline meniscus & 96 & 96 & 0.6395 \\
\hline Punching efficiency & 59 & 61 & 0.5667 \\
\hline Time shaver was used & 90 & 37 & $<0.00001$ \\
\hline Shaver movement & 72.5 & 23.5 & 0.0013 \\
\hline Total time of blind shaving & 0 & 0 & 0.4622 \\
\hline Area of cartilage damage $\left(\mathrm{mm}^{2}\right)$ & 58 & 0 & 0.0392 \\
\hline Shaving efficiency & 48 & 70 & 0.0501 \\
\hline Overall score & 4.7 & 7.2 & 0.0004 \\
\hline Unsuccessful grasping attempts & 10.5 & 2 & 0.0157 \\
\hline Covered distance: camera & 45.9 & 13.55 & 0.0006 \\
\hline Covered distance: grasper & 87.4 & 35.65 & 0.0004 \\
\hline Covered distance: open grasper & 79.2 & 14.35 & $<0.00001$ \\
\hline Roughness: camera & 0 & 0 & 0.1838 \\
\hline Roughness: grasper & 12.5 & 12 & 0.2456 \\
\hline Roughness: open grasper & 12.5 & 12 & 0.0521 \\
\hline Total time & 151.5 & 64 & 0.0001 \\
\hline Overall score & 7.2 & 7.5 & 0.0502 \\
\hline $\begin{array}{l}\text { Percentage of damaged surface } \\
\text { covered }\end{array}$ & 85 & 81 & 0.1517 \\
\hline $\begin{array}{l}\text { Percentage of effective } \\
\text { microfractures }\end{array}$ & 100 & 100 & 0.2594 \\
\hline $\begin{array}{l}\text { Maximum depth of } \\
\text { microfractures }(\mathrm{mm} .)\end{array}$ & 4 & 4 & 0.3517 \\
\hline $\begin{array}{l}\text { Minimum distance between } \\
\text { microfractures (mm.) }\end{array}$ & 1 & 2 & 0.2355 \\
\hline $\begin{array}{l}\text { Number of microfractures in } \\
\text { healthy area }\end{array}$ & 0 & 0 & 0.2841 \\
\hline Covered distance: awl & 99.9 & 41.65 & 0.0001 \\
\hline Covered distance: camera & 57.05 & 25.5 & 0.0094 \\
\hline Roughness: awl & 0 & 0 & 0.6711 \\
\hline Roughness: camera & 0 & 0 & 0.4303 \\
\hline Total time & 260.5 & 143 & 0.0003 \\
\hline Overall score & 6.1 & 8.6 & $<0.00001$ \\
\hline Covered distance: camera & 82.05 & 24.35 & 0.0004 \\
\hline Covered distance: probe & 107.9 & 34.3 & 0.0004 \\
\hline Roughness: camera & 1 & 0 & 0.0336 \\
\hline Roughness: probe & 5 & 4 & 0.1953 \\
\hline Femoral tunnel distance (mm.) & 7 & 3 & 0.0095 \\
\hline Tibial tunnel distance (mm.) & 5 & 1.5 & 0.0079 \\
\hline Total time & 239.5 & 99.5 & 0.0003 \\
\hline
\end{tabular}




\section{Cureus}

\section{TABLE 2: Comparison of novice and expert performance scores on advanced tasks}

Efficiencies are expressed in percentage, time in seconds, distance in centimeter (unless $\mathrm{mm}$ is specified), and roughness in Newton. The overall score is calculated automatically by the simulator software, with a range of 0 to 10 . Other scores are calculated as a percentage.

NA: Not available; ACL: anterior cruciate ligament

The expert group had superior performance on 65 of the 75 variables analyzed for the seven advanced tasks (87\%). Most of these differences were statistically significant $(48 / 75 ; 64 \%)$. The performance was similar between groups for nine tasks. The novice group had superior performance on only one variable (1.3\%), in the microfractures procedure task: percentage of damaged surface covered. This difference was not statistically significant $(\mathrm{p}=0.1517)$. Table 3 provides a summary of the performance metrics for advanced tasks.

\begin{tabular}{|c|c|c|c|c|}
\hline Task & $\begin{array}{l}\text { Experts had superior } \\
\text { performance }\end{array}$ & $\begin{array}{l}\text { Similar } \\
\text { performance }\end{array}$ & $\begin{array}{l}\text { Novices had superior } \\
\text { performance }\end{array}$ & Total \\
\hline 1 Arthroscopic visual examination & 6 & 0 & 0 & 6 \\
\hline $\begin{array}{l}2 \text { Diagnostic arthroscopy with advance probe } \\
\text { palpation }\end{array}$ & 11 & 0 & 0 & 11 \\
\hline $\begin{array}{l}3 \text { Diagnostic arthroscopy of random intra- } \\
\text { articular pathology }\end{array}$ & 6 & 0 & 0 & 6 \\
\hline 4 Meniscectomy of a radial lateral tear & 21 & 3 & 0 & 24 \\
\hline 5 Loose body extraction & 8 & 1 & 0 & 9 \\
\hline 6 Femoral condyle repair with microfractures & 5 & 5 & 1 & 11 \\
\hline 7 Tunnel placement for ACL reconstruction & 8 & 0 & 0 & 8 \\
\hline Total & 65 & 9 & 1 & 75 \\
\hline
\end{tabular}

TABLE 3: Summary of all 75 variables for the seven advanced tasks, comparing the performance of expert and novice surgeons

ACL: anterior cruciate ligament

The experts had a statistically significant faster completion time for all seven advanced tasks. Expert completion times were roughly half those of the novices for four tasks (Figure 3). 


\section{Cureus}

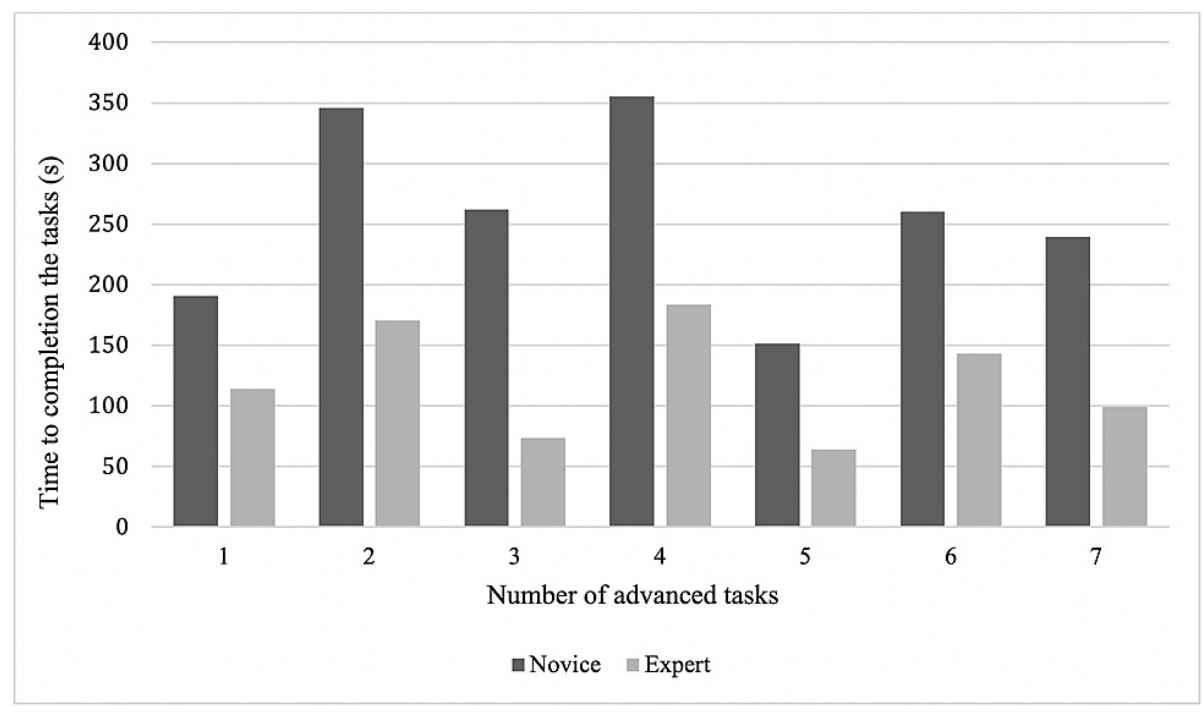

\section{FIGURE 3: Median completion time for advanced tasks}

Median completion time for advanced tasks, comparing novice and expert surgeons. Time is expressed in seconds. The differences for all tasks were statistically significant $(p<0.05)$.

Multivariate logistic regression was performed using a priori probability ratios. A total of 27 variables were statistically defined as the most representative of performance differences between the two groups. Based on the scores for these variables, the model then predicted the group into which each participant would be classified. The model classified all of the students as novices and all of the experienced surgeons as experts, as shown in Table 4. In other words, the error rate was zero for both groups. Classification accuracy remained without errors even when the analysis was performed without prior information about the distribution; that is when the performance of the 30 subjects was analyzed with a $50 \%$ probability of belonging to either group, not the $33 \%$ and $66 \%$ a priori probability ratio used before.

\begin{tabular}{|c|c|c|}
\hline True role & Classified as Novice & Classified as Expert \\
\hline Novice & $100 \%$ & $0 \%$ \\
\hline Expert & $0 \%$ & $100 \%$ \\
\hline
\end{tabular}

\section{TABLE 4: Multivariate logistic regression}

The multivariate logistic regression used the performance variables provided by the virtual reality surgical simulator to predict the true role of each surgeon with $100 \%$ accuracy.

\section{Discussion}

The performance of the expert group was superior to that of the novices for the vast majority of the variables analyzed, and these differences were largely significant. The difference between expert and novice scores were statistically significant for $50 \%$ of the basic and $64 \%$ of the advanced task variables. The differences were most pronounced for advanced tasks that required the surgeons to use expert judgment and fluidly integrate various motor skills to evaluate or treat a simulated pathology, rather than to merely demonstrate a single motor skill in isolation. This level of mastery represents the most advanced level in the Fitts and Posner model, that is, the autonomous stage of learning [11], and at least the proficient nor the expert stage of Dreyfus $[12,13]$. This result is logical given that the advanced tasks required the students to complete surgeries that they had not previously performed, while the basic tasks did not demand such a high level of dexterity. Furthermore, the parameters for the basic tasks do not have a direct clinical correlation, unlike the advanced tasks that are quite similar to real surgical procedures. Therefore, the skill of the expert surgeons was better demonstrated in these advanced tasks, reflected in faster completion times and more skillful handling of the instruments. Specifically, the expert scores reflected shorter punch, camera, and probe paths and fewer errors that would be likely to produce intra-articular damage, such as camera collisions with tissue or palpation of irrelevant structures. Expert scores were also superior in terms of roughness of instrument use, steadiness, blind use of instruments, and efficiency of shaver use, resulting in less cartilage damage. Finally, from a safety standpoint, the novice group committed more errors than expert practitioners; the 
hope is that the students would learn from the feedback and avoid these errors when working with real patients.

To assess construct validity defined as the capacity of the system to effectively measure the ability simulated, we assessed the ability of the performance metrics to discriminate between expert and novice surgeons [21]. As a first step, we compared the median performance scores of the two groups. These results were statistically significant; however, the preferred method for assessing the validity of a surgical simulator is multivariate logistic regression using a priori probability ratios, which was performed as the second step in our study. This analysis demonstrated $100 \%$ accuracy in classifying the participants as novices or experts, providing a robust validation of the simulator. The analysis was first conducted using the a priori probabilities of $33 \%$ and $66 \%$ for the expert and novice categories, respectively, as the study sample included 10 experts and 20 novices. However, the classification remained $100 \%$ accurate when a priori probabilities of $50 \%$ were applied, offering an even stronger validation of the discrimination capacity of the simulator.

As an advantage, the virtual reality arthroscopy simulator can be used as a reliable and objective tool to evaluate the acquisition of surgical competencies. To pass the simulated tasks [18], the resident must provide a practical demonstration of the skill, effectively performing the task in a simulated manner, corresponding to the third level in the Miller model for assessing competence [17]. This learning model "shows how" corresponds to the evaluation of a performed skill rather than knowledge. Miller theorized four levels of skill or clinical competency acquisition, ordered from least to greatest complexity. The first two levels of the pyramid correspond to the demonstration of acquired knowledge, which may be memorized but not yet applied. The first level is "knowing," that is, having knowledge about the procedure, followed by "knowing how to," in which the subject is capable of describing how to perform a task but may not be able to practically demonstrate the skill. The final two levels both require a practical demonstration of the skill. At the third level, "shows how," subjects can demonstrate the task. Progressing towards this level of learning is the area in which the simulation system is most useful, as it allows subjects to perform tasks that they had previously studied in order to acquire and demonstrate a skill or competency. Finally, the peak of the pyramid is "doing," which in this context means demonstrating the skill in real patients. Formal practical assessments are rarely used in surgical training programs. The practical evaluations used are generally subjective, with the teaching surgeon assessing and finally approving the performance of his or her students in the operating room. Surgical simulators provide a more objective evaluation of learned skills. This approach may also be useful in sports medicine training and in the certification of orthopedic surgeons.

We had a positive impression practicing with the virtual reality simulator, although the initial cost can be high, the maintenance of the equipment was not. We highlight, as well as previous studies [4], the great availability, transversality, and the opportunity to practice at any time without the need for expert supervision.

A strength of this study is a larger sample as compared to previous research on this topic [22,23,28,29]. In prior virtual reality simulation studies, the samples of novices were often large, but the number of experts evaluated has tended to be low. Another strength is the depth of performance variables analyzed. While previous research has tended to focus on completion time, this study analyzed 119 variables separately and included 27 variables in the multivariate analysis, providing more support for the construct validity of the tool.

One limitation of this study was the lack of clinical outcomes correlation. It would be interesting to evaluate the transfer of learning to the operating room or to assess the performance of residents who complete virtual reality simulation training. The literature is limited in these types of studies; our intention is to continue in that way.

\section{Conclusions}

The ARTHRO Mentor ${ }^{\mathrm{TM}}$ knee arthroscopy simulator demonstrates construct validity, accurately discriminating novice from expert surgeons.

Virtual reality simulation to teach surgical skills in knee arthroscopy is a valid, useful, and accessible tool. The system provides standardized training for residents. These findings support the surgical simulation practice in a safe environment while providing feedback that should lead, we hope, to an effective transfer of learning to real surgical situations.

\section{Additional Information \\ Disclosures}

Human subjects: Consent was obtained or waived by all participants in this study. Ethics Committee of the University of Chile Clinical Hospital issued approval 74-2017. All participants signed an informed consent form prior to study enrollment. Animal subjects: All authors have confirmed that this study did not involve animal subjects or tissue. Conflicts of interest: In compliance with the ICMJE uniform disclosure form, all 
authors declare the following: Payment/services info: All authors have declared that no financial support was received from any organization for the submitted work. Financial relationships: All authors have declared that they have no financial relationships at present or within the previous three years with any organizations that might have an interest in the submitted work. Other relationships: All authors have declared that there are no other relationships or activities that could appear to have influenced the submitted work.

\section{References}

1. Kim S, Bosque J, Meehan JP, Jamali A, Marder R: Increase in outpatient knee arthroscopy in the united states: a comparison of national surveys of ambulatory surgery, 1996 and 2006. J Bone Joint Surg Am. 2011, 93:994-1000. 10.2106/JBJS.I.01618

2. Tay C, Khajuria A, Gupte C: Simulation training: a systematic review of simulation in arthroscopy and proposal of a new competency-based training framework. Int J Surg. 2014, 12:626-33. 10.1016/i.ijsu.2014.04.005

3. Atesok K, Mabrey JD, Jazrawi LM, Egol KA: Surgical simulation in orthopaedic skills training. J Am Acad Orthop Surg. 2012, 20:410-22. 10.5435/JAAOS-20-07-410

4. Papanikolaou IG, Haidopoulos D, Paschopoulos M, Chatzipapas I, Loutradis D, Vlahos NF: Changing the way we train surgeons in the 21th century: a narrative comparative review focused on box trainers and virtual reality simulators. Eur J Obstet Gynecol Reprod Biol. 2019, 235:13-8. 10.1016/j.ejogrb.2019.01.016

5. Olsen MA, Nepple JJ, Riew KD, Lenke LG, Bridwell KH, Mayfield J, Fraser VJ: Risk factors for surgical site infection following orthopaedic spinal operations. J Bone Joint Surg Am. 2008, 90:62-9. 10.2106/JBJS.F.01515

6. Institute of Medicine (US) Committee on Quality of Health Care in America: To Err is Human Building a Safer Health System. Kohn LT, Corrigan JM, Donaldson MS (ed): National Academies Press , Washington, DC; 2000. 10.17226/9728

7. Amirthanayagam TD, Emery RJH: Primum non nocere: risk assessment for new surgical procedures . J Shoulder Elbow Surg. 2014, 23:1417-8. 10.1016/j.jse.2014.06.056

8. Shelton J, Kummerow K, Phillips S, et al.: Patient safety in the era of the 80-hour workweek . J Surg Educ. 2014, 71:551-9. 10.1016/j.jsurg.2013.12.011

9. Reznick RK, MacRae H: Teaching surgical skills--changes in the wind . N Engl J Med. 2006, 355:2664-9. 10.1056/NEJMra054785

10. Fitts PM, Posner MI: Human Performance. Brooks/Cole, Belmont, CA; 1967.

11. Kopta JA: The development of motor skills in orthopaedic education . Clin Orthop Relat Res. 1971, 75:80-5. 10.1097/00003086-197103000-00011

12. Sadideen H, Plonczak A, Saadeddin M, Kneebone R: How educational theory can inform the training and practice of plastic surgeons. Plast Reconstr Surg Glob Open. 2018, 6:e2042. 10.1097/GOX.0000000000002042

13. Dreyfus SE: The five-stage model of adult skill acquisition. Bull Sci Technol Soc. 2004, 24:177-81. 10.1177/0270467604264992

14. Satava RM: Virtual reality surgical simulator. The first steps. Surg Endosc. 1993, 7:203-5. 10.1007/BF00594110

15. Ericsson KA: Deliberate practice and the acquisition and maintenance of expert performance in medicine and related domains. Acad Med. 2004, 79:S70-81. 10.1097/00001888-200410001-00022

16. Nagendran M, Gurusamy KS, Aggarwal R, Loizidou M, Davidson BR: Virtual reality training for surgical trainees in laparoscopic surgery. Cochrane Database Syst Rev. 2013, 2013:CD006575. 10.1002/14651858.CD006575.pub3

17. Miller GE: The assessment of clinical skills/competence/performance . Acad Med. 1990, 65:63-7. 10.1097/00001888-199009000-0004510.1097/00001888-1

18. Jacobsen ME, Andersen MJ, Hansen CO, Konge L: Testing basic competency in knee arthroscopy using a virtual reality simulator: exploring validity and reliability. J Bone Joint Surg Am. 2015, 97:775-81. 10.2106/JBJS.N.00747

19. Bartlett JD, Lawrence JE, Stewart ME, Nakano N, Khanduja V: Does virtual reality simulation have a role in training trauma and orthopaedic surgeons?. Bone Joint J. 2018, 100-B:559-65. 10.1302/0301620X.100B5.BJJ-2017-1439

20. Hetaimish B, Elbadawi H, Ayeni OR: Evaluating simulation in training for arthroscopic knee surgery: a systematic review of the literature. Arthroscopy. 2016, 32:1207-20.e1. 10.1016/j.arthro.2016.01.012

21. Sugden C, Aggarwal R: Assessment and feedback in the skills laboratory and operating room . Surg Clin North Am. 2010, 90:519-33. 10.1016/i.suc.2010.02.009

22. Lopez G, Martin DF, Wright R, et al.: Construct validity for a cost-effective arthroscopic surgery simulator for resident education. J Am Acad Orthop Surg. 2016, 24:886-94. 10.5435/JAAOS-D-16-00191

23. Colaco HB, Hughes K, Pearse E, Arnander M, Tennent D: Construct validity, assessment of the learning curve, and experience of using a low-cost arthroscopic surgical simulator. J Surg Educ. 2017, 74:47-54. 10.1016/j.jsurg.2016.07.006

24. Boutefnouchet $\mathrm{T}$, Laios $\mathrm{T}$ : Transfer of arthroscopic skills from computer simulation training to the operating theatre: a review of evidence from two randomised controlled studies. SICOT J. 2016, 2:4. $10.1051 /$ sicotj/2015039

25. Martin KD, Belmont PJ, Schoenfeld AJ, Todd M, Cameron KL, Owens BD: Arthroscopic basic task performance in shoulder simulator model correlates with similar task performance in cadavers. J Bone Joint Surg Am. 2011, 93:e1271-5. 10.2106/JBJS.J.01368

26. Castillo R, Buckel E, León F, et al.: Effectiveness of learning advanced laparoscopic skills in a brief intensive laparoscopy training program. J Surg Educ. 2015, 72:648-53. 10.1016/j.jsurg.2015.01.016

27. Castillo R, Alvarado J, Moreno P, Billeke P, Martínez C, Varas J, Jarufe N: Validation of a visual-spatial secondary task to assess automaticity in laparoscopic skill. J Surg Educ. 2018, 75:1001-5. 


\section{Cureus}

10.1016/j.jsurg.2017.11.007

28. Aïm F, Lonjon G, Hannouche D, Nizard R: Effectiveness of virtual reality training in orthopaedic surgery . Arthroscopy. 2016, 32:224-32. 10.1016/j.arthro.2015.07.023

29. Tofte JN, Westerlind BO, Martin KD, Guetschow BL, Uribe-Echevarria B, Rungprai C, Phisitkul P: Knee, shoulder, and fundamentals of arthroscopic surgery training: validation of a virtual arthroscopy simulator. Arthroscopy. 2017, 33:641-6.e3. 10.1016/j.arthro.2016.09.014 